\title{
Awareness of Adult Basic Life Support among Graduates in a Medical College of Kathmandu
}

\author{
Dr. Siddharth Dixit, ${ }^{1}$ Dr. Sirjana Dahal, ${ }^{2}$ Dr. Punam Basnet Dixit, ${ }^{3}$ Dr. Geshu Lama ${ }^{4}$ \\ ${ }^{1}$ Department of Prosthodontics, Kathmandu Medical College and Teaching Hospital, Bhaktapur, Nepal; \\ ${ }^{2}$ Department of Community and Public Health Dentistry, Kathmandu Medical College and Teaching Hospital, Bhaktapur, Nepal; \\ ${ }^{3}$ Department of Conservative Dentistry and Endodontics, Kathmandu Medical College and Teaching Hospital, Bhaktapur, Nepal; \\ ${ }^{4}$ Department of Forensic Medicine, Kathmandu Medical College and Teaching Hospital, Kathmandu, Nepal.
}

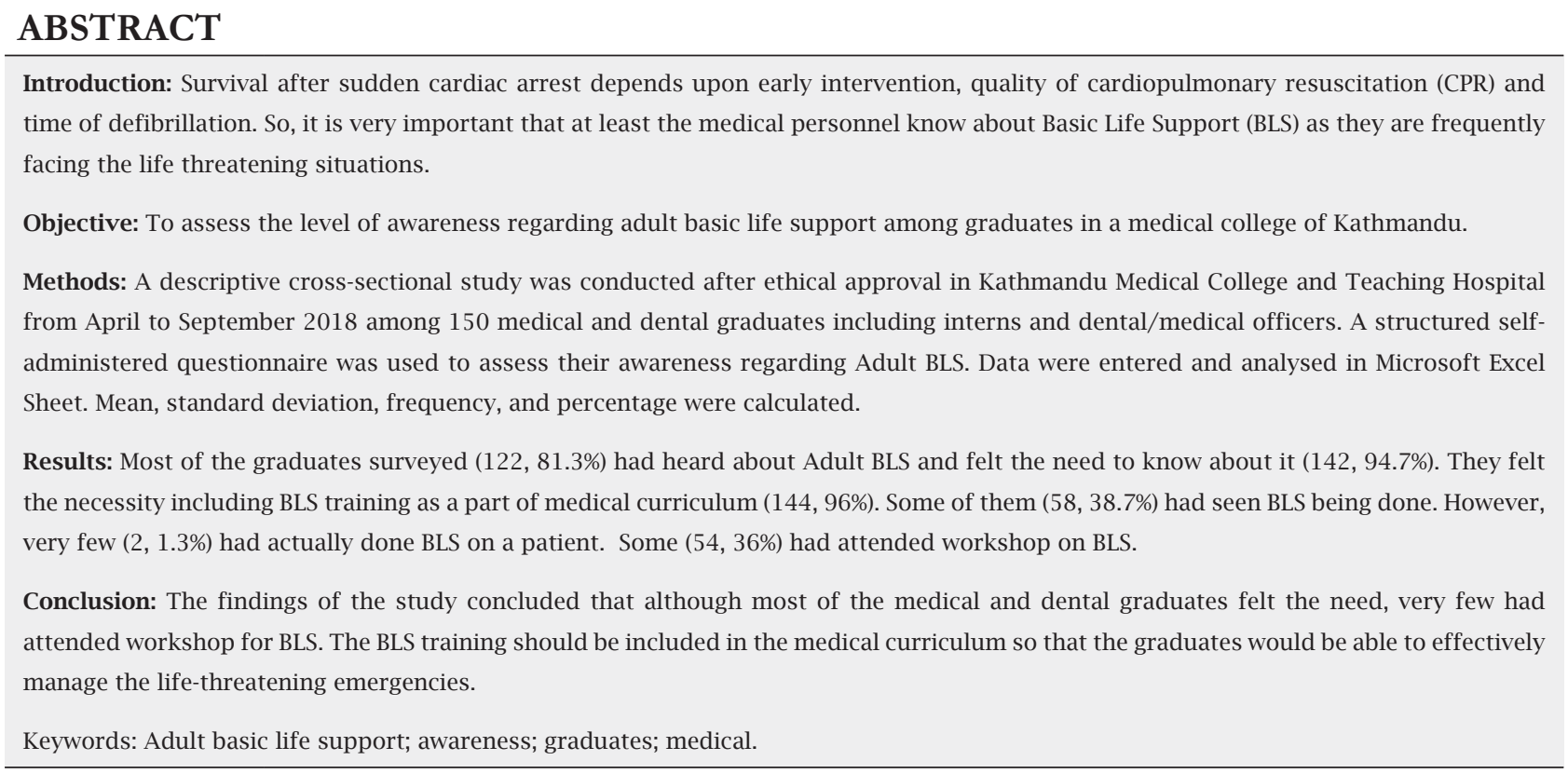

\section{INTRODUCTION}

Basic Life Support (BLS) comprises of recognising signs of sudden cardiac arrest, heart attack, stroke, and foreign body airway obstruction. It also includes the process of cardiopulmonary resuscitation (CPR); and defibrillation with an automated external defibrillator. ${ }^{1}$ The key component of resuscitation process is BLS, which includes adequate maintenance of ventilation and circulation thereby helping in survival of patients with respiratory or cardiac arrest.,3

Cardiovascular diseases (CVDs) are the most common cause of premature death and a major disease burden globally. ${ }^{4}$ In Nepal, total deaths from CVDs have almost doubled from 1990 to 2017, making CVDs the most significant cause of

\footnotetext{
Correspondence:

Dr. Siddharth Dixit

Department of Prosthodontics, Kathmandu Medical College and Teaching Hospital, Bhaktapur, Nepal.

email: siddharthdxt@gmail.com

\section{Citation}

Dixit S, Dahal S, Dixit PB, Lama G. Awareness of Adult Basic Life Support among Graduates in a Medical College of Kathmandu. J Nepal Soc Perio Oral Implantol. 2020 Jul-Dec;4(8):73-7.
}

death and Disability Adjusted Life Years lost. ${ }^{5}$ Therefore, BLS technique should be essentially known by the community people, and mandatorily by the health care providers so that they can save lives in case of emergency. ${ }^{6}$

Training for BLS should be provided to all personnel working in health sector. In Nepal, there is paucity of studies assessing the BLS preparedness of medical/dental graduates during or after completion of their studies before they reach out as health care providers. Hence, the present study aims to assess the level of awareness regarding adult BLS among graduates of Kathmandu Medical College and Teaching Hospital.

\section{METHODS}

A descriptive cross-sectional study was conducted in Kathmandu Medical College and Teaching Hospital from April to September 2018, after receiving ethical approval from the same institution. Total of 150 medical and dental graduates including two batches of interns, dental, and medical officers were selected by convenience sampling method. Graduates under influence of drugs and under psychiatric medication were excluded. Informed consent was sought from the study participants prior to data collection. 
A structured closed-ended questionnaire was formulated containing questions regarding awareness of adult basic life support obtained from published studies., ${ }^{1,7}$ The questionnaire was pretested among 18 first batch dental officers. Some modifications in questionnaire were made where responses were not found appropriate. The final questionnaire consisted of two sections: Demographic profile and questions regarding awareness of Adult BLS.

Sample size was calculated using formula: $\mathrm{n}=\mathrm{Z}^{2} \mathrm{pq} / \mathrm{e}^{2}$, where $\mathrm{Z}=1.96$ at $95 \%$ confidence interval, $\mathrm{p}=$ prevalence (knowledge of setups where BLS can be performed) $=89.98 \%, 7 \mathrm{q}=100-\mathrm{p}, \mathrm{e}=$ permissible error (absolute) $=5 \%$. Placing these values in the provided formula, $\mathrm{n}=138.49$. Adding $5 \%$ non-response rate, total sample size $=145.41 \approx 150$ was considered.

The self-administered questionnaire was provided to two batches of interns and medical/dental officers. The filled sheets were received from them the next day. Incompletely filled questionnaires were also considered and analysed accordingly as questions not answered. Data were entered and analysed in Microsoft Excel Sheet. Frequency and percentage were calculated for each response.

\section{RESULTS}

Out of total study participants, 106 (70.6\%) belonged to age group 18-21 years and 28 (18.6\%) to age group 22-25 years.
However, 16 (2.6\%) did not disclose their age. Majority of study participants were females $(102,68 \%)$. Most of them (122, 81.3\%) had heard about Adult BLS. Nearly half of them (74, 49.3\%) could explain about adult BLS. Most of them, 142 (94.7\%) felt the need to know about BLS as graduates. However, 4 (2.7\%) felt the knowledge about BLS was not needed and 4 (2.7\%) of the students did not answer. Majority $(144,96 \%)$ felt the necessity to include BLS training as part of medical curriculum. More than half of the graduates (122, 81.3\%) thought that BLS should be done only in a hospital setting (Table 1).

Majority of the respondents felt that the main reason behind lack of knowledge about BLS is the non-existing provision of professional training to the medical/dental graduates (108, 72\%) followed by busy/vast curriculum (30,20\%) and lack of interest $(6,4 \%)$. Some of them $(6,4 \%)$ did not respond to this question. Most of the graduates $(76,50.7 \%)$ could arrange head tilt, chin lift, and checking pulse in orderly sequence. However, 48 (32\%) could not arrange the three actions orderly and 26 (17.3\%) did not respond to the question. The responses to number of chest compression per minute, ratio of chest compression to breathe, site of chest compression, dialing number for emergency, and rating oneself for BLS knowledge given by graduates are depicted in Figure 1-5.

Table 1: Responses to questions regarding awareness of adult BLS, $\mathbf{n}(\%)$.

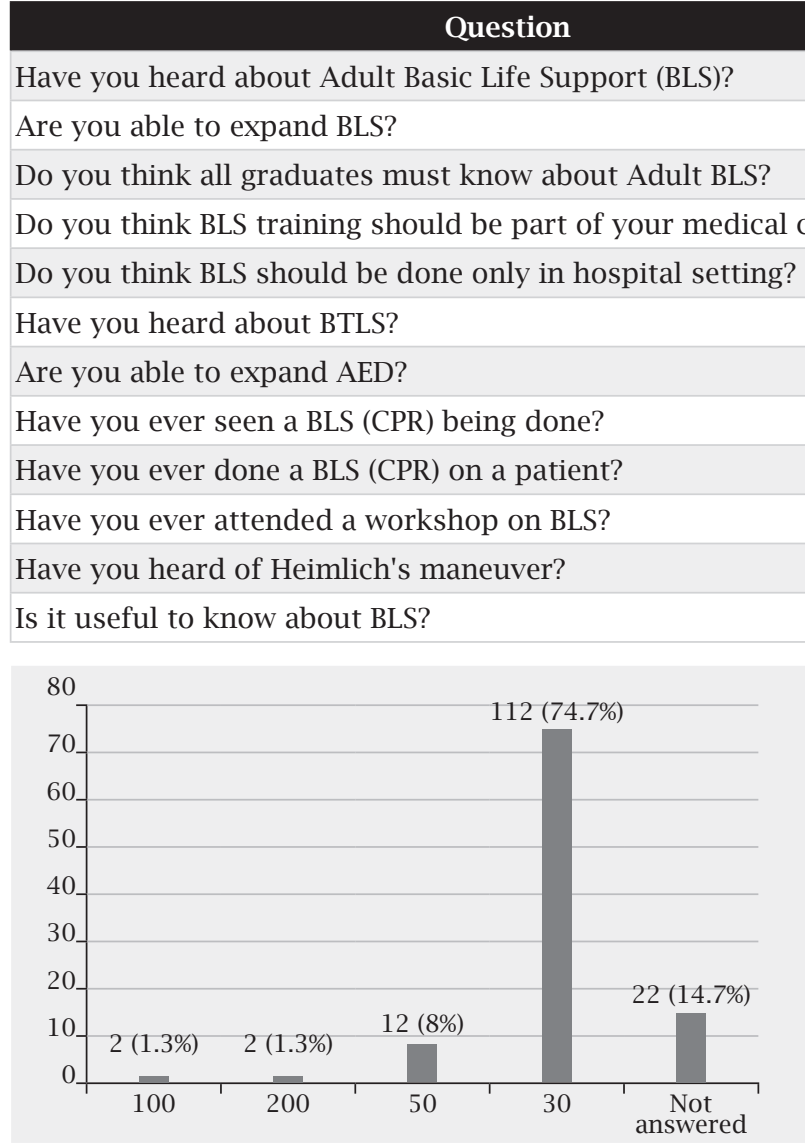

Figure 1: Responses to number of compressions to be done in one minute in an adult.
No

Not answered

\begin{tabular}{|c|c|c|}
\hline $122(81.3)$ & $18(12)$ & $10(6.7)$ \\
\hline $74(49.3)$ & $76(50.7)$ & - \\
\hline $142(94.7)$ & $4(2.7)$ & $4(2.7)$ \\
\hline $144(96)$ & $6(4)$ & - \\
\hline $28(18.7)$ & $122(81.3)$ & - \\
\hline $28(18.7)$ & $102(68)$ & $20(13.3)$ \\
\hline $28(18.7)$ & $122(81.3)$ & - \\
\hline $58(38.7)$ & $90(60)$ & $2(1.3)$ \\
\hline $2(1.3)$ & $142(94.7)$ & $6(4)$ \\
\hline $54(36)$ & $88(58.7)$ & $8(5.3)$ \\
\hline $36(24)$ & $102(68)$ & $12(8)$ \\
\hline $146(97.3)$ & $4(2.7)$ & - \\
\hline
\end{tabular}

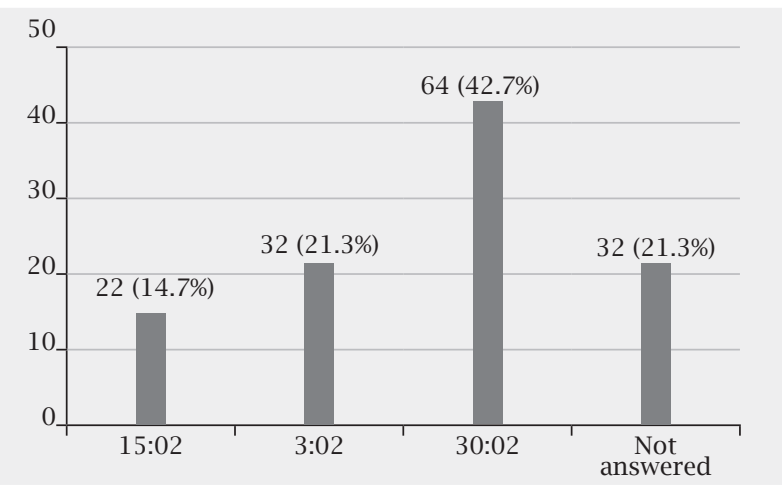

Figure 2: Responses to ratio of chest compressions to breath in adults. 


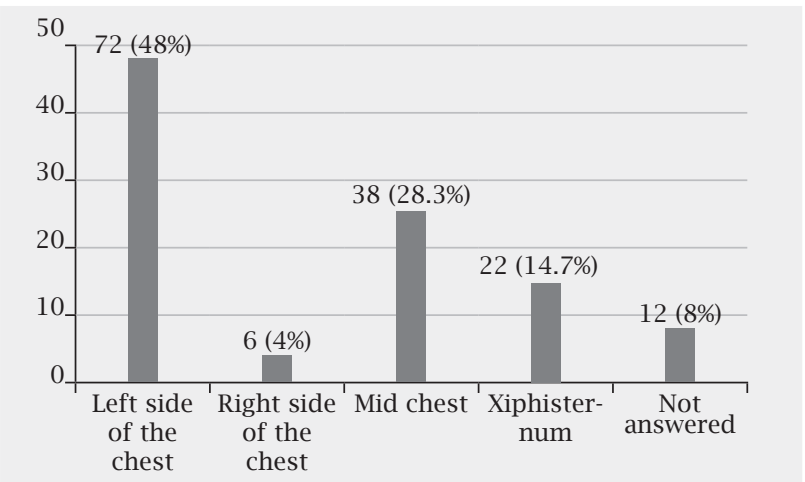

Figure 3: Responses to location for chest compression.

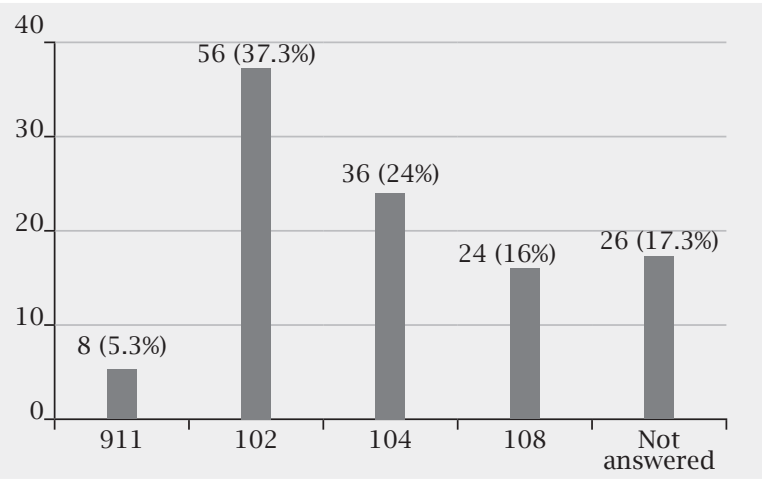

Figure 4: Responses to dialing number for help in case of a medical emergency.

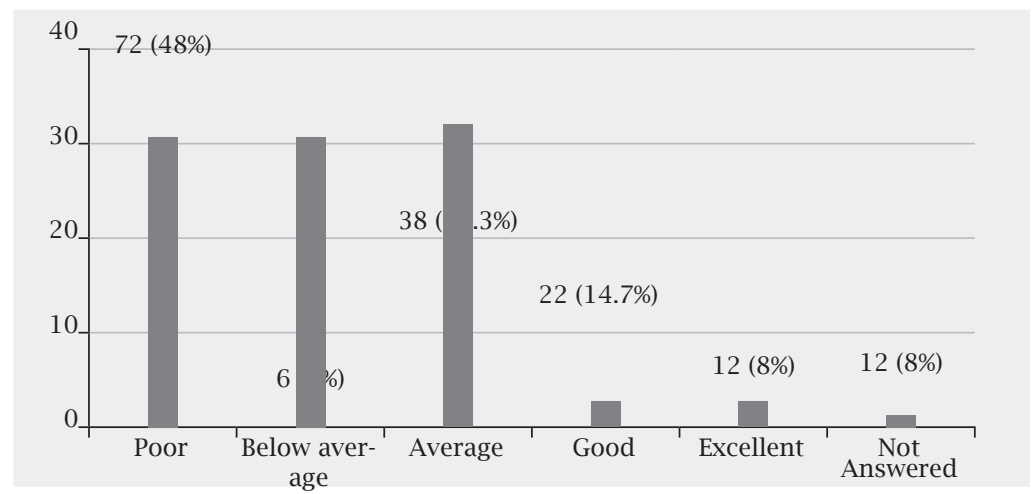

Figure 4: Responses to rating himself/herself regarding BLS knowledge.

\section{DISCUSSION}

There should be sound knowledge and adequate skills to perform BLS by every health care professional. ${ }^{8}$ It is because life-threatening emergencies can occur at any time, at anywhere, and to anyone. Tragic consequences may result due to lack of training and inability to cope with medical emergencies. Thus, all health professionals including dentists must be well prepared to manage such situations. ${ }^{9}$ This study was conducted to assess the awareness among medical/dental graduates of Kathmandu Medical College and Teaching Hospital regarding adult BLS. In the present study, more than $80 \%$ of the medical and dental graduates had heard the term BLS. However, few $(18,12 \%)$ had no idea about it and some $(10,6.7 \%)$ did not bother to answer the question. Only 74 (49.3\%) could expand BLS which is in contrast to study done by Sangamesh et al. where $82.61 \%$ of medical interns and $66.67 \%$ of dental interns could explain about BLS. ${ }^{7}$ In a study done by Narayan et al., average knowledge about BLS was seen in dental interns and post graduate students. ${ }^{8}$ A study by Irfan et al. showed $67.1 \%$ of doctors and only $35 \%$ of dentists having an adequate amount of knowledge regarding BLS. ${ }^{10}$

Although they were not able to explain BLS, most of the respondents in this study $(142,94.7 \%)$ felt that all graduates must know about it and BLS training should be included as a part of their curriculum (144, 96\%). Comparable results were found in a study by Alotaibi et al. where 93.6\% of dental students and staffs felt the need to know about BLS and wished to have its training in their curriculum. ${ }^{11}$ All the medical and dental interns (100\%) of a study done by Sharma and Attar favoured inclusion of BLS in their academic curriculum. ${ }^{12}$ These similar findings from different studies from different countries stress on the need for structured BLS training in undergraduate medical and dental program.

Only few respondents of the current study $(28,18.7 \%)$ heard about Basic Trauma Life Support (BTLS) and could expand AED as Automated external defibrillator. In contrast, majority of health care interns (81.2\%) of a study by Saquib et al. could tell the full form of AED.13 Some of the respondents in this study $(58,38.7 \%)$ saw CPR being done but only 2 (1.3\%) had actually given CPR to patients by themselves.

Some participants in this study $(54,36 \%)$ attended a workshop on BLS. However, more than $90 \%$ of the medical and dental interns had received some form of training regarding BLS in a study by Saquib et al. ${ }^{13}$ Training is required for any health care professional as it helps to gain knowledge and skills regarding BLS. Authors from different studies have recommended that healthcare professions should have hands-on courses on BLS regularly so that they 
can refresh knowledge and master their skills. ${ }^{14,15}$ In this study, majority of the participants $(146,97.3 \%)$ felt that it is useful for them to know about BLS.

Some of the graduates $(36,24 \%)$ in the current study had heard of Heimlich's manoeuvre. Most of them (108, 72\%) felt that the main reason behind the lack of knowledge about BLS was the non-existing provision of professional training to the medical and dental graduates followed by busy/vast curriculum (30, 20\%) and lack of interest (6, 4\%). Similarly, Arsati et al. found lack of training and updates in an undergraduate program as the common cause for lack of knowledge.16 In a study done by Alotaibi et al., the most common justifications indicated by the participants for their lack of knowledge and skills were busy curriculum followed by no professional training available. ${ }^{11}$

Only two participants (1.3\%) of this study could answer the correct number of compressions to be done in one minute in an adult (approximately 100 compressions per minute). Most of the graduates $(64,42.7 \%)$ gave the correct response to chest compression to breathe ratio in adults (30:2) which was similar to the study done by Aroor et al. ${ }^{17}$ where $40.8 \%$ gave correct answer to the same question. Only 38 (25.3\%) could give the correct location of chest compression (mid chest) in this study. However, more than half of the respondents (56\%) in a study by Irfan et al. could give the correct position for the same. ${ }^{10}$ Number for help in case of medical emergency could be correctly dialed by 56 (37.3\%) participants in the present study and by $56.3 \%$ in a study done by Aroor et al. ${ }^{17}$

When they were asked to rate themselves regarding BLS knowledge, most of the respondents $(48,32 \%)$ marked their knowledge as average followed by below average (46, $30.7 \%)$ and poor $(46,30.7 \%)$. Very few $(4,2.7 \%)$ considered themselves as having excellent and good knowledge. Similarly, in a study done by Sharma et al. medical and dental interns had poor knowledge about BLS. ${ }^{12}$ The findings from these studies highlight the need for formal training and workshops for BLS so that each and every health professional can be confident to efficiently manage the medical emergency conditions.

This study has some limitations. This study has been conducted in a single medical institution and convenience sampling method has been used to select the study participants due to which the study findings cannot be generalised to the whole medical and dental graduates of Nepal. Also, comparison of awareness between medical and dental graduates was not done as the number of medical and dental graduates was not comparable.

\section{CONCLUSION}

The findings of the study concluded that most of the medical and dental graduates had some idea about BLS. Most of them felt the need of BLS training as a part of medical curriculum. However, very few of them had attended the workshop for BLS. Most of the graduates' had theoretical knowledge on BLS but had very little practical exposure on performing the same. Therefore, it is very essential to include BLS training in the medical and dental curriculum so that the graduates would be able to effectively manage the life-threatening emergencies.

\section{ACKNOWLEDGEMENT}

The authors would like to thank all the interns and medical and dental officers for their active participation in the study.

\section{Conflict of Interest: None.}




\section{REFERENCES}

1. Chandrasekaran S, Kumar S, Bhat SA. Awareness of basic life support among medical, dental, nursing students and doctors. Indian J Anaesth. 2010 Mar;54(2):121-6.

2. Sasson C, Rogers MA, Dahl J, Kellermann AL. Predictors of survival from out-of-hospital cardiac arrest: a systematic review and metaanalysis. Circulation Cardiovasc Qual Outcomes 2010;3:63-81.

3. Phillips PS, Nolan JP. Training in basic and advanced life support in UK medical schools: Questionnaire survey. Br Med J. 2001;323(7303):22-3.

4. Moraga P. Causes of Death Collaborators Global, regional and national age-sex specific mortality for 264 causes of death, 1980-2016: a systematic analysis for the Global Burden of Disease Study 2016. Lancet. 2017;390(10100):1151-210.

5. Bhattarai S, Aryal A, Pyakurel M, Bajracharya S, Baral P, Citrin D, et al. Cardiovascular Disease Trends in Nepal-An Analysis of Global Burden of Disease Data 2017. Int J Cardiol Heart Vasc. 2020 Oct;30:100602-8.

6. Forouzan A, Verki MM, Khabazipour A, Ahmadi K. Basic life support awareness among resident doctors, medical students, nursing experts, health care providers, and their assistants in Southwest Iran. Med Stud. 2018 Jan 1;34(3):203-10.

7. Sangamesh NC, Vidya KC, Pathi J, Singh A. Awareness, attitude, and knowledge of basic life support among medical, dental, and nursing faculties and students in the university hospital. J Int Soc Prev Community Dent. 2017 Jul-Aug;7(4):161-7.

8. Narayan DP, Biradar SV, Reddy MT, BK S. Assessment of knowledge and attitude about basic life support among dental interns and postgraduate students in Bangalore city, India. World J Emerg Med. 2015;6(2):118-22.

9. Marsden AK. Guidelines for cardiopulmonary resuscitation basic life support revised recommendations of the resuscitation council (UK). Br Med J. 1989;299:442-5.

10. Irfan B, Zahid I, Khan MS, Khan OA, Zaidi S, Awan S, et al. Current state of knowledge of basic life support in health professionals of the largest city in Pakistan: a cross-sectional study. BMC Health Serv Res. 2019 Nov 21;19(1):865-71.

11. Alotaibi O, Alamri F, Almufleh L, Alsougi W. Basic life support: Knowledge and attitude among dental students and Staff in the College of Dentistry, King Saud University. Saudi J Dent Res. 2016 Jan 1;7(1):51-6.

12. Sharma R, Attar NR. Adult basic life support (BLS) awareness and knowledge among medical and dental interns completing internship from deemed university. Nitte Univ J Health Sci. 2012 Sep;2(03):06-13.

13. Saquib SA, Al-Harthi HM, Khoshhal AA, Shaher AA, Al-Shammari AB, Khan A, Al-Qahtani TA, Khalid I. Knowledge and attitude about basic life support and emergency medical services amongst healthcare interns in university hospitals: a cross-sectional study. Emerg Med Int. 2019 Mar 3;2019:9342892.

14. Farah R, Stiner E, Zohar Z, Zveibil F, Eisenman A. Cardiopulmonary resuscitation surprise drills for assessing, improving and maintaining cardiopulmonary resuscitation skills of hospital personnel. European J Emerg Med. 2007 Dec 1;14(6):332-6.

15. Morgan R, Westmoreland C. Survey of junior hospital doctors' attitudes to cardiopulmonary resuscitation. Postgrad Med J. 2002 Jul 1;78(921):413-5.

16. Arsati F, Montalli VA, Florio FM, Ramacciato JC, da Cunha FL, Cecanho R et al. Brazilian dentists' attitudes about medical emergencies during dental treatment. J Dent Educ. 2010;74(6):661-6.

17. Aroor AR, Saya RP, Attar NR, Saya GK, Ravinanthanan M. Awareness about basic life support and emergency medical services and its associated factors among students in a tertiary care hospital in South India. J Emerg Trauma Shock. 2014 Jul;7(3):166-9. 